\title{
Development of individual differences in stress responsiveness: an overview of factors mediating the outcome of early life experiences
}

\author{
Sanne E. F. Claessens • Nikolaos P. Daskalakis • \\ Rixt van der Veen • Melly S. Oitzl • E. Ronald de Kloet • \\ Danielle L. Champagne
}

Received: 22 June 2010 /Accepted: 25 November 2010 /Published online: 18 December 2010

(C) The Author(s) 2010. This article is published with open access at Springerlink.com

\begin{abstract}
Rationale Human epidemiology and animal studies have convincingly shown the long-lasting impact of early life experiences on the development of individual differences in stress responsiveness in later life. The interplay between genes and environment underlies this phenomenon.

Objectives We provide an overview of studies investigating the impact of early life experiences on the development of individual differences in neuroendocrine stress responsiveness in adulthood and address (1) impact of environment on later stress phenotypes, (2) role of genetic factors in modulating the outcome of environment, and (3) role of nonshared environmental experience in the outcome of gene $\times$ environment interplays. We present original findings where we investigated the influence of nonshared experiences in terms of individual differences in maternal care received, on the development of stress phenotype in later life in rats.

Results Environmental influences in early life exert powerful effects on later stress phenotypes, but they do not always lead to expression of diseases. Heterogeneity in response is explained by the role of particular genetic factors in modulating the influence of environment. Nonshared experiences are important in the outcome of gene $\times$
\end{abstract}

Electronic supplementary material The online version of this article (doi:10.1007/s00213-010-2118-y) contains supplementary material, which is available to authorized users.

S. E. F. Claessens $(\bowtie) \cdot$ N. P. Daskalakis $\cdot$ R. van der Veen $\cdot$ M. S. Oitzl • E. R. de Kloet • D. L. Champagne

Division of Medical Pharmacology, Leiden/Amsterdam Center for

Drug Research and Leiden University Medical Center, Gorlaeus

Laboratories, Leiden University,

P.O. Box 9502, 2300 RA Leiden, The Netherlands

e-mail: s.claessens@lacdr.leidenuniv.nl environment interplays in humans. We show that nonshared experiences acquired through within-litter variation in maternal care in rats predict the stress phenotype of the offspring.

Conclusion The outcome of early experience is not deterministic and depends on several environmental and genetic factors interacting in an intricate manner to support stress adaptation. The degree of "match" and "mismatch" between early and later life environments predicts resilience and vulnerability to stress-related diseases, respectively.

Keywords Brain · Development · Gene $\times$ environment interaction $\cdot$ Glucocorticoids $\cdot$ Maternal care $\cdot$ Rat $\cdot$ Stress

\section{Introduction}

Here, we provide an overview of studies investigating the impact of early life experiences on the development of individual differences in neuroendocrine stress responsiveness in adulthood. Evidence for this phenomenon is largely provided by research on developmental programming of the stress system. This field of research investigates the mechanisms underlying the impact of environmental stressors or exogenous glucocorticoids during critical periods of development on sensitivity to stress and vulnerability to stress-related diseases throughout the lifespan.

The term "developmental programming" derives from the concept of "developmental origin of adult diseases" introduced more than 20 years ago by Barker and colleagues and was based on a large body of epidemiological research documenting the relationship between low birth weight and an increased risk of developing metabolic 
and cardiovascular disorders (Barker 1992a, b, c). These findings led to what is currently known as the Barker hypothesis (Barker 1997). This concept has been since extended to include "developmental programming of the hypothalamic-pituitary-adrenal (HPA) axis" (Andrews and Matthews 2004; de Kloet et al. 2005; Matthews 2002; Meaney et al. 2007; Seckl 2008). This is achieved through the actions of specific environmental cues acting at a specific time during development, and which result in permanent alterations in the functioning of the HPA axis (Andrews and Matthews 2004; de Kloet et al. 2005; Matthews 2002; Meaney et al. 2007; Oitzl et al. 2010; Seckl 2008). Why is this relevant at all? In addressing this question, preclinical and clinical evidence suggests that this remarkable phenomenon has relevance for the etiology of some of the major mental disorders triggered by stressful life events, including depression and posttraumatic stress disorder (Heim et al. 2008; Heim et al. 2004; Meaney et al. 2007; Seckl 2008).

Traditionally, this research has focused on detrimental consequences of stress but far less on the ability to develop resilience to stress or stress-related diseases. Recent findings are challenging this view and suggest that the outcome of early experience is not necessarily deterministic nor can it be perceived as good or bad, in absolute term. Several environmental, cognitive, and genetic inputs are involved in an intricate manner in the modulation of the outcome of early experiences. We first address instances where environmental influences in early life exert powerful effects on later stress phenotypes, even to the extent of overriding an individual's genetic attributes. Secondly, we address the evidence showing the crucial role of particular genetic constituents in modulating the outcome of these environmental effects. Thirdly, we address the increasingly recognized role of nonshared environmental experiences that are unique to the individual, in the outcome of gene $x$ environment interplays.

\section{Environmental influences}

Animal models: postnatal manipulations

The field of developmental programming has a long history of studies on the importance of early experiences for the development and establishment of individual phenotypes (Levine 1957). This led to the emergence of a line of studies in rodents, primates, and humans until today. Broadly, these studies can be divided into investigating either prenatal or postnatal manipulations. Here, we will focus on the impact of several postnatal paradigms. For a review on the impact of prenatal manipulations, we refer to previous literature (Glover et al. 2009; Kinsella and Monk
2009; Lupien et al. 2009; Maccari and Morley-Fletcher 2007).

Early handling In the 1950s, the late Seymour Levine made a fascinating discovery (Levine 1957). He exposed neonate rat pups to daily handling sessions, which consisted of brief maternal separation periods $(<15 \mathrm{~min})$ between postnatal day (pnd) 1 and 21. The outcome of these manipulations was surprising and unexpected at the time. Levine, and others, found that early handling (EH) induced long-lasting changes in adult phenotype such as HPA axis hyporesponsiveness (Levine 2005; Meaney et al. 1985; Meerlo et al. 1999), reduced emotionality (Meerlo et al. 1999), and increased cognitive performance (Kosten et al. 2007) in EH animals as compared to rats raised in undisturbed laboratory conditions, i.e., nonhandled (NH). However, the use of such control groups was recognized to be problematic later; see reviews (Macri et al. 2004; Macri and Wurbel 2006; Pryce et al. 2005). Because the EH procedure was considered at that time to be a stressful experience, these findings challenged the dominant theory stating that early life stress invariably contributes to the development of "emotional instability". Instead, the findings from Levine demonstrated that, in some instances (e.g., via EH), exposure to "moderate stress" in early life appeared to be beneficial for the infant by promoting a greater ability of the organism to adapt to psychological and physiological stressors in adulthood (Levine 1957). This same principle also serves as the basis for the stress inoculation-induced resilience theory developed several years later (Levine and Mody 2003; Lyons et al. 1998; Lyons et al. 1999).

Maternal separation Over the years, new paradigms were introduced in an attempt to also study the mechanisms underlying developmental programming following exposure to more "adverse" experiences (Plotsky and Meaney 1993). Maternal separation (MS) consists of prolonged periods of maternal absence ranging from 1 to $24 \mathrm{~h}$. The reported effects of MS appear to be more controversial compared to the effects of $\mathrm{EH}$, in part because of the substantial variety in different experimental procedures across different laboratories in terms of duration, frequency, age of onset of the separation, and the choice of control group (Lehmann and Feldon 2000; Lehmann et al. 2002; Rosenfeld et al. 1992). Nevertheless, MS appeared to "program" the functioning of the HPA axis. As expected, this manipulation was reported to yield a more severe outcome, opposing the effects of EH, including HPA hyperresponsiveness following stress (Plotsky and Meaney 1993), increased emotionality (Kalinichev et al. 2002b), altered sensitivity to opioids (Kalinichev et al. 2002a), and impaired cognitive performance (Levine 2005). For an 
extensive review of early life models, see Levine (2005) and Schmidt (2010).

\section{Maternal mediation hypothesis}

The use of the EH model raised an important question: How can short episodes of maternal absence result in such profound and enduring effects on adult stress phenotype? The "maternal mediation hypothesis" was proposed for the first time as part of the mechanism underlying the lasting effects of EH by Smotherman and Bell (1980). This theory postulates that the outcome of postnatal manipulations (such as EH, MS, and $\mathrm{NH}$ ) is mediated by changes in maternal behavior directed towards the offspring upon reunion after a given period of mother-infant separation (Denenberg 1999). It was observed that brief $(15 \mathrm{~min})$ episodes of EH resulted in increased active maternal care as shown during observation periods over the entire day. Longer periods $(4 \mathrm{~h})$ of MS yielded an increase in active maternal care only directly after reunion of the dam with the pups but not at any other time point, leading overall to differences in the amount/quality of maternal care received by EH versus MS pups (Pryce et al. 2001). This suggests that the amount and quality of maternal care, at least in part, mediate effects of EH and MS on functioning of the HPA axis in the offspring.

However, certain findings challenged this theory. Although these studies clearly demonstrate the importance of maternal care for epigenetic programming of gene expression and thus provide support in favor of the maternal mediation hypothesis, for instance, Macri and coworkers (Macri et al. 2004) reported inconsistencies in the maternal mediation hypothesis. They showed an overall increase in maternal care following both EH and MS. Their findings revealed that following MS dams increase their care to such an extent that they fully compensate for the separation time and reach a level comparable to EH dams. Since EH and MS offspring display significantly different endocrine and behavioral stress responses in later life, it was concluded that maternal care cannot be the only mediator driving the effects of the postnatal manipulations (Macri et al. 2004; Macri and Wurbel 2006).

Tang and colleagues (Tang et al. 2006) have also tested the maternal mediation hypothesis in an original study. Using a paradigm in which half of the litter is stimulated by exposure to a novel environment, whereas the other half stays in the nest, Tang and colleagues have dissociated between the two potential sources of contribution to the development of the neonate - one source being the indirect effect of maternal care toward the stimulated (noveltyexposed) versus the home-staying offspring, and the other source being the direct effect of stimulating the pups through novelty exposure. It was reported that the novelty-exposed pups showed functional enhancement in term of cognition and endocrine responsiveness. However, this enhancement occurred in the absence of increased maternal care toward the novelty-exposed pups. Therefore, these findings suggest a revised maternal modulation hypothesis stating that (1) nonshared experiences, unique to the individual, have a direct effect on the offspring, potentially leading to alterations in adult phenotype, and (2) maternal behaviors can attenuate or enhance these effects, modulating the enduring effects on phenotype (Tang et al. 2006). These findings clearly indicate the importance of including the study of nonshared factors in addition to the study of shared factors within a litter, the later often being the only variable studied in these paradigms. This issue will be addressed into more detail later in this review (see Nonshared environmental influences section).

Naturally occurring variation in maternal care

The most compelling set of evidence on the importance of the amount and quality of maternal care on the development of the stress-regulating system came from the elegant work of Meaney and colleagues (Liu et al. 1997). Employing a noninvasive naturalistic approach, they studied the impact of naturally occurring variation in maternal care on the development of the HPA axis in rodents. This model is based on extreme differences among lactating rats in the frequency of licking and grooming (LG) they provide to their pups. They show that variation in the amount of maternal LG, a form of tactile stimulation, modulates the development of the structure and function of the neural circuitry underlying stress regulation, emotionality, and cognitive processes (Bagot et al. 2009; Caldji et al. 1998; Champagne et al. 2008; Liu et al. 2000; Liu et al. 1997; Smit-Rigter et al. 2009). Reminiscent of the outcome of $\mathrm{EH}$, offspring of high, relative to low LG dams, show decreased behavioral and endocrine responsiveness to stress, reduced emotionality, and enhanced performance in tests of spatial learning and object recognition (Caldji et al. 1998; Liu et al. 2000; Liu et al. 1997). These effects are largely reversed with cross-fostering, in which the biological offspring of a high LG mother is cross-fostered to a low LG mother or vice versa. This suggests that variation in maternal care transfers phenotypic differences to the offspring in a nongenetic way, providing a clear demonstration of an environmental effect mediated by maternal care (Francis et al. 1999).

It should be noted that the early environment not solely consists of maternal factors. Other environmental factors also contribute in shaping later life outcome by affecting developmental trajectories. Several studies have indicated the importance of peer interactions. For instance, it has 
been reported that monkeys deprived of peer contact show abnormal development in terms of social behavior and emotional responses (Harlow 1969). Additionally, Branchi and colleagues, using a rodent model for social enrichment, have attempted to disentangle the effects of maternal versus peer interactions. Their findings suggest an important role for peer interaction in shaping the social and emotional phenotype in later life (Branchi 2009).

\section{The stress-hyporesponsive period}

The outcome of early life experiences largely depends on the timing, frequency, and duration an individual is exposed to particular environmental experiences (Champagne et al. 2009; Enthoven et al. 2008a; Meaney and Aitken 1985; van Oers et al. 1998a). For instance, the impact of EH procedures on adult phenotype appears to be more profound if they are performed during the early postnatal period as compared to later in the postnatal period (Meaney and Aitken 1985). This is important since the early postnatal period coincides with onset of the stress-hyporesponsive period (SHRP). The SHRP begins in the first postnatal days and terminates around pnd 14 in rodents (Levine 2005; Schmidt 2010). During this period, the neonate's adrenals are hyporesponsive to mild stressors (e.g., novelty exposure) that are capable to trigger a profound glucocorticoid response in the adult. While during the SHRP the adrenals are hyporesponsive, the brain does respond to novelty and other type of stressors. Maternal presence via active maternal care and feeding is suggested to actively regulate the responsiveness of the neonate's HPA axis during the SHRP (Levine 1994; Suchecki et al. 1993). Therefore, maternal presence serves to "buffer" the impact of stressors on neonates.

MS episodes will exert stronger impact especially if they occur within rather than outside the SHRP. The outcome of MS can be reversed by mimicking and reinstating aspects of maternal behavior during the separation procedure. For instance, MS-induced increase in glucocorticoid secretion was prevented by reinstating feeding via a cannula connected to the stomach, while artificial tactile stimulation gently administered with a paint brush during the separation period was required to restore pituitary adrenocorticotropic hormone release and c-fos mRNA expression in the paraventricular hypothalamus (van Oers et al. 1998b).

Recent findings from our laboratory revealed another issue to take into consideration when designing a study including the use of postnatal manipulations. Such issue concerns the impact of repeated MS during the SHRP. In a series of experiments, Enthoven and colleagues reported that neonates, as expected, responded to 8-h MS with a slow increase in HPA axis activation reaching a significant increase in glucocorticoids after $4 \mathrm{~h}$. Interestingly, if the 8-h MS was daily repeated, the MS-induced HPA axis response became readily desensi- tized. From a psychological perspective, these findings suggest that pups may be able to predict the return of the dam and the reinstatement of maternal care, hence preventing the MS-induced HPA activation (Enthoven et al. 2008b).

It is also of significant relevance where the pup experiences repeated MS. We showed that repeated MS in the home environment result in habituation of the HPA axis activity in response to maternal absence. Remarkably, we observed that these pups continue to respond to an additional 30-min exposure to a novel environment. We propose that after repeated MS episodes, the neonate's HPA axis stays on alert and will be activated only when the return of the dam cannot be predicted (Enthoven et al. 2008b). Specifically, under conditions of repeated home MS, the adrenals become hyperresponsive to novelty. However, if the 8-h MS procedure is performed by placing the pup repeatedly in a novel rather than the home nest, the adrenals becomes hyporesponsive to novelty stress (Daskalakis et al., unpublished observations).

Another important aspect is the state of maturity of the neonate's nervous system. The developing brain is extremely sensitive to all types of sensory input such as those incurred through maternal LG. This is primarily due to the abundant proliferation of synaptic connections in the postnatal periods. Timing is therefore crucial in the newborn's brain. During the SHRP, the developing brain is able to integrate sensory input into circuits that control, for example, attachment to the caregiver (Moriceau and Sullivan 2004), or fear-motivated behaviors, and stressinduced HPA axis activation (Wolke 1987). Therefore, the maturity of the sensory system during the SHRP will also influence the degree by which glucocorticoids, environmental cues (e.g., maternal LG), or stress (e.g., EH and MS) will alter the development of these circuits.

The mechanisms underlying the ability of pups to make predictions about the environment are unclear. One possibility involves aspect of the neonate's circuitry (locus coeruleus and olfactory cortex) dedicated to odor learning (Moriceau and Sullivan 2004). Since neonate rodents depend on their mother for survival, this system facilitates the attachment to the caregiver. During the SHRP, when glucocorticoid levels are usually low, the neonate shows an increased ability to form odor preferences to maternal and other odors, and a decreased ability to form odor aversions, even to negative stimuli. This is believed to facilitate the establishment of a secure relationship with the caregiver (Moriceau and Sullivan 2006). When glucocorticoid levels increase and SHRP is disrupted, for instance due to MS, the amygdala gets activated, and a switch to odor aversion is observed (Moriceau et al. 2009; Raineki et al. 2010).

From these findings, a number of inferences can be made. Firstly, the predictability of the manipulation and the context in which they occur (novel vs. home, as also 
indicated by Tang and colleagues (Tang et al. 2006)) play a role in the outcome of the manipulation. This knowledge contributes to the understanding of the substantial variation in outcome of postnatal manipulations such as EH and MS as reported above in this review. Secondly, interpretation of the findings gathered from several animal models ranging from rodents and guinea pigs to nonhuman primates, which are born with differential degrees of brain maturity at birth, needs to be analyzed carefully before any comparison with humans can be made (Kapoor et al. 2006).

\section{Epigenetic programming of the HPA axis}

It was reported that changes in HPA axis activity and hippocampus-specific changes in GR expression levels, which are a prominent outcome of the EH paradigm, also occurred in response to naturally occurring variation in maternal care. Differential glucocorticoid responsiveness causing changes in synaptic plasticity is believed to underlie the vast array of neuroendocrine (Liu et al. 1997), behavioral (Caldji et al. 1998; Menard and Hakvoort 2007; Zhang et al. 2005), and cognitive alterations (Bagot et al. 2009; Champagne et al. 2008) observed in these early life stress paradigms (Levine 2005; Szyf et al. 2007).

However, a major breakthrough in the history of the field of developmental programming came with the discovery of epigenetic modifications in the promoter area of the GR gene, revealing a mechanism underlying these environmentally driven effects on later life stress phenotype. It was shown that increased levels of maternal LG during the first week of life alter the methylation pattern of the GR gene in the hippocampus of the offspring (Weaver et al. 2004). These changes persist into adulthood and alter the expression of the GR throughout life via modification of the chromatin structure. Crossfostering of the offspring shows a complete reversal of methylation patterns, demonstrating that DNA can be structurally modified (without alterations to sequence) through environmental influences, thus leading to changes in gene expression (Meaney and Szyf 2005; Weaver et al. 2004).

The significance of these findings in the field of psychiatry is unclear, but recent studies in humans revealed that epigenetic programming of the HPA axis via changes in DNA methylation of GR may occur in human infants born to mothers who experienced depression during pregnancy (Oberlander et al. 2008). Additionally, there are indications of epigenetic regulation of GR in the brains of individuals with a history of adverse childhood experiences who committed suicide following a stressful life event (McGowan et al. 2009).

Evidence for developmental programming in humans

For obvious reasons, human studies on the programming effects of early life experiences are less numerous and more complex compared to the previously described animal studies. Since it would be unethical to expose the developing infant to the experimental manipulations that are imposed on the animals, advancement in this field relies on naturally occurring events and retrospective reports.

A series of studies from the groups of Heim and colleagues as well as Rinne and colleagues have convincingly shown the impact of early adverse events, such as childhood abuse, on alterations in the functioning of the HPA axis, as a consequence leading to an increased risk to develop psychiatric dysfunctions (Heim et al. 2000; Heim et al. 2008; Heim et al. 2004; Rinne et al. 2002). A doseresponse relationship has been described between the number of experienced childhood adversities and mental health score in later life (i.e., probability of lifetime depressive disorders; Chapman et al. 2004; Edwards et al. 2003).

Besides severe forms of adversity such as emotional neglect accompanied by sexual or physical abuse, there is also evidence that milder forms of adversity are associated with increased risk for stress related-pathologies. For instance, not only early life socioeconomic disadvantage (Wickrama et al. 2005) but also subtle differences in parenting style (Feinberg et al. 2007; Feinberg et al. 2000; Reiss et al. 1995) appear to affect health status of the individual in later life.

Therefore, there is no doubt that early adversity plays a crucial role in programming the development of a range of physical and psychiatric disorders. As it is clearly shown in animal studies, vulnerability to diseases is likely to be mediated (at least partially) via the effects of early adversity on the functioning of the HPA axis. Several studies show the association between early life adversity and enduring sensitization of the responsiveness of the HPA axis in humans. For instance, alterations in basal as well as stressinduced HPA axis activity at different life stages have been reported in human subjects exposed to adversity in early life (Gutteling et al. 2005; Heim et al. 2000; O'Connor et al. 2005; Rinne et al. 2002).

\section{Maternal influences in humans}

As with animal models, it has also been demonstrated in humans that the mother (or another caregiver) plays a mediating role in the regulation of the HPA axis in children (Gunnar and Donzella 2002). Several studies show that when children are exposed to adequate care, they display diminished cortisol responsiveness, increased threshold to evoke a cortisol response to various stressors (Gunnar and Donzella 2002), and a better cortisol recovery after stress (i.e., glucocorticoid negative feedback; Albers et al. 2008). This is explained by suggesting that children, under high care-giving conditions, anticipate that a caregiver will 
protect them, and therefore, they feel able to cope with a threatening situation (Gunnar and Donzella 2002). This phenomenon could be an analog of the rodent SHRP, although the time window for this period is less well defined in humans (Gunnar and Donzella 2002). More lines of evidence for maternal mediation come from a study showing that prenatal stress is associated with a reduction in hippocampal volume only in combination with low levels of postnatal maternal care. This suggests that the impact of prenatal experiences is mediated by the postnatal maternal environment (Buss et al. 2007).

\section{The role of genetic variation in the outcome of environmental influences}

\section{Genetic modulation in humans}

Recent evidence has revealed that despite strong environmental influences, not every individual exposed to adverse experiences (up to $50 \%$ of cases) develops a stress-related psychiatric illness in later life (Bonanno and Mancini 2008; Caspi and Moffitt 2006; Rutter 2009, 2010). Clearly, the degree of sensitivity to stress and vulnerability to stressrelated illnesses varies between individuals of a given population or even within the same family (Caspi and Moffitt 2006; Rutter 2009, 2010). That may be explained by inheritance of particular genetic factors (genetic variants commonly found in the population) acting as modulators of the outcome of environmental influences. While the idea of a direct causal link between one given gene and one psychiatric disease has been discarded, it is becoming increasingly clear that a combination of several genetic factors can play a significant role in modulating the outcome of environmental influence (Caspi et al. 2010; Caspi and Moffitt 2006; Rutter et al. 2006). For instance, several genetic polymorphisms have been uncovered and found to modulate the sensitivity to stress and vulnerability to stress-related diseases. One of the most investigated gene variants in psychiatry is the functional polymorphism in the promoter region of the serotonin transporter gene (5-HTT; Caspi et al. 2010; Caspi and Moffitt 2006; Rutter et al. 2006). Inheritance of the "short" allele variant results in lower expression levels of 5-HTT in a dose-dependent manner and is associated with increased HPA axis activity. Moreover, carriers of the short allele display increased neuronal activity in amygdala fear pathways and decreased gray matter volume in amygdala and frontal cortex. These alterations appear to be correlated with increased susceptibility to depression and suicide in individuals with a specific history of adverse childhood experiences and/or later stressful life events (Caspi et al. 2010; Caspi and Moffitt 2006; Rutter 2010; Rutter et al. 2006). This represents a powerful demonstration of the impact of genetic variation on the outcome of environmental influences. Several other examples of genetic variation modulating the outcome of childhood and adolescent adverse experiences have been reported (for reviews, see Caspi et al. (2010), Caspi and Moffitt (2006), Rutter (2008), and Rutter et al. (2006)). These include for instance the functional polymorphism in the promoter region of the monoamine oxidase A gene, which moderates the effect of child maltreatment (Caspi et al. 2002; Caspi and Moffitt 2006), and the catechol-O-methyltransferase, which moderates the impact of adolescent cannabis use on development of adult psychosis (Caspi and Moffitt 2006; Caspi et al. 2005).

Importantly, twin and adoption studies have revealed that genetic factors mostly appear to exert significant effects in the context of adverse environmental conditions (Heim and Nemeroff 1999). This is in agreement with the "diathesis-stress model" (Gutman and Nemeroff 2003; Zubin and Spring 1977), which posits that genetic factors that increase vulnerability to stress/diseases are more likely to be expressed under adverse/stressful environments than under more favorable conditions (Barr et al. 2004; Caspi et al. 2010; Caspi and Moffitt 2006; Ouellet-Morin et al. 2009; Rutter et al. 2006). This is well illustrated by the case of the 5-HTT variant described above (Caspi et al. 2010; Caspi and Moffitt 2006; Rutter 2008; Rutter et al. 2006) and in a study of Ouellet-Morin and colleagues (OuelletMorin et al. 2009). The authors showed that genetic factors accounted for most of the variation in cortisol levels in infants, as measured by (basal) morning cortisol secretion, only in the context of adverse familial experience (OuelletMorin et al. 2009), thus demonstrating the modulating impact of genetic factors on HPA axis development in humans. However, the same group showed that for other measures of stress sensitivity such as HPA reactivity (cortisol) to stress, adverse environmental influences strongly mediated the outcome of HPA axis development with little effects of genetic factors. This suggests that environmental influences can sometimes constrain the modulating impact of genetic factors (Ouellet-Morin et al. 2008). These findings are important for the implementation of intervention programs, where the focus is on attempting to prevent, reverse, and/or reduce familial environmental adversity (Anderson et al. 2003; Doyle et al. 2009).

Furthermore, the spectrum of genetic factors modulating environmental influences not only is restricted to genes coding for proteins but also includes the nonprotein-coding genetic factors (often referred to as junk DNA; Plomin and Davis 2009). Such DNA elements can directly or indirectly influence gene $\times$ environment interplays and lead to increased vulnerability to psychiatric disorders (Plomin and Davis 2009; Rutter 2008; Rutter et al. 2006). In addition, DNA copy number variation, where multiple 
copies of certain genes or segments of DNA are inserted or deleted from particular locations on a given chromosome, represents an untapped source of genetic modulation of environmental influences (Merikangas et al. 2009). Various forms of DNA structural variations have been recently found to play a role in the etiology of psychopathologies such as depression and schizophrenia (Duan et al. 2010; Merikangas et al. 2009; Saus et al. 2010; Weiss 2009; Weiss et al. 2009). It is therefore important to consider all forms of genetic factors as possible modulators of environmental influences on the development of individual differences in stress responsiveness and susceptibility to stressrelated diseases.

Genetic modulation in maternal care studies

Also, in animal models, there is clear evidence for genetic modulation of environmental manipulations. For instance, it has been reported that certain strains of mice appear to benefit more from neonatal manipulations such as EH compared to others. This effect can be partially explained by strain-specific differences in maternal mediation (Anisman et al. 1998). Besides substantial variation between dams from the same strain (as previously described in this review), it has been clearly shown that rodents also show strain-dependent variation in maternal care, leading to low and high caring strains (Carlier et al. 1982).

By cross-fostering inbred mice strains to such a low or high caring mother strain, it is possible to determine the contribution of genetic as well as early environmental factors in the development of adult phenotypes (van der Veen et al. 2008). van der Veen and colleagues have investigated this issue. They selected two mice strains based on their maternal care style. One strain showed low $(\mathrm{AKR})$, and the other high $(\mathrm{C} 3 \mathrm{H})$ innate levels of maternal care, therefore providing a significantly different early environment to the offspring. Pups from two unrelated strains (providing different genetic background), namely $\mathrm{DBA} / 2 \mathrm{~J}$ and $\mathrm{C} 57 \mathrm{BL} / 6 \mathrm{~J}$ mice, were cross-fostered to these low and high caring mother strains. Indeed, it was observed that AKR dams displayed lower levels of maternal care toward the offspring as compared to $\mathrm{C} 3 \mathrm{H}$ dams. However, when the cross-fostered strains were tested in adulthood, a difference in their sensitivity to the "programming" effects of early life environment on adult phenotype was observed. For instance, irrespective of being raised by a low or high maternal care strain, the adult phenotype of C57 mice remained unchanged, indicating a relative resistance to early environmental factors. In contrast, DBA mice raised by a low caring mother strain significantly differed from DBA mice raised by a high caring mother strain in terms of cocaine intake and immobility response in the forced swim test, thus indicating sensitivity to early environmental factors. These results demonstrate a strong effect of genetic background in modulating maternal environmental influences during early life.

\section{Nonshared environmental influences}

The outcome of gene $\times$ environment interplays described above can also be mediated by more subtle factors, previously underappreciated in their ability to shape the outcome of studies in the field of developmental programming. Even though these factors will add another level of complexity to an already multifaceted field, they should not be neglected. Here, we will focus on the role of nonshared environmental factors on the development of the HPA axis using findings from a recent study in our laboratory.

\section{Shared and nonshared environmental factors}

We acknowledge that there are inconsistencies in the way the terms shared and nonshared are used in human as opposed to animal research. The term "nonshared environment" is always used to describe differences in environment. However, in human studies, it is frequently used to describe differences in environment of siblings within a family, for instance due to differential parenting (Feinberg et al. 2000; Reiss et al. 1995). On the contrary, in animal studies, it is used to describe differences between litters such as being raised by a high or low LG dam (Liu et al. 1997). In our manuscript, whenever we mention "shared" or "nonshared", we meant to describe factors "shared" or "nonshared" by individual members within a litter.

Shared and nonshared environmental factors

in developmental programming

Traditionally, the field of developmental programming is focused on investigating the impact of early experiences that differ between litters or families, but are usually considered to be similar (shared) for individual members within the litter or family. Currently, experimental models where the impact of shared and nonshared environmental factors within the litter can be manipulated and/or studied in the laboratory are scarce.

For instance, as described earlier in this review, Meaney and colleagues have convincingly shown the profound and long-lasting impact of naturally occurring variations in early environment (Liu et al. 1997; Macri et al. 2008). However, due to methodological considerations, the association between the early experiences and the phenotype of the offspring in later life is based solely on maternal behaviors (i.e., high vs. low LG dam). Even though the difference between high and low LG offspring is usually 
referred to as being caused by a nonshared factor, it is assumed that this factor is experienced in a similar way (shared) by all the individual pups within a litter.

However, previous studies by Menard and colleagues using this model show that pups from the same litter display substantial variation in behavioral phenotype later in life (Menard and Hakvoort 2007). This is interesting since it was assumed that these pups were reared and have therefore perceived (shared) the same maternal care environment. This suggests that there are also nonshared factors within the litter that lead to phenotypic variation in the offspring.

In human literature, over the years, an increasing number of studies have indeed reported that parenting style varies not only between families but also within the family. This variation in parenting within the family leads to experiences that are unique to the individual and are nonshared by other members of the family. These nonshared factors are an important correlate for the development of stress-related pathologies in later life (Feinberg et al. 2000; Reiss et al. 1995). Additionally, the same researchers have shown that parenting toward one child is linked with an opposite outcome on the child's sibling as on the target child, suggesting that harsh parenting toward one child could make the other sibling less prone to develop psychopathology. This is referred to as the "sibling barricade" and suggests that the perception of parenting might be more powerful than the absolute amount/quality of parenting you are subjected to (Feinberg et al. 2000; Reiss et al. 1995).

Other human studies by Tremblay and colleagues have shown that in conditions characterized by low familial adversity, differences in cortisol reactivity in young children were mostly accounted for by genetic and nonshared environmental factors. Shared environmental factors did not account for variance in cortisol reactivity (OuelletMorin et al. 2008). These findings illustrate the importance of studying the impact of these previously unrecognized subtle nonshared, individual-specific early life experiences within a family or litter, on the development of vulnerability to stress-related disorders.

Modeling shared and nonshared environmental factors in animals

Since experimental models where the impact of nonshared environmental factors within the litter can be manipulated and/or studied in the laboratory are scarce, we have attempted to tackle this issue by investigating an extension of the maternal care model.

To address this issue, we have performed a detailed assessment of the amount and quality of maternal care received by each individual pup within the litter (representing the nonshared influence) during the first week of life. In addition, we also describe the maternal phenotype (repre- senting shared influence). Moreover, we have investigated whether within-litter variation in maternal care can predict phenotypic differences in endocrine responsiveness to acute novelty stress in the offspring later in life. This novel approach is meant to complement previous studies on variation in maternal care between litters and might help to explain gene $x$ environment interplays on an individual level. The methodological details of this experiment can be found in Online Resource 1.

Nonshared environment within the litter predicts stress phenotype in later life

We report that maternal LG is not homogeneously distributed among individual pups within the litter, suggesting that particular pups consistently receive higher or lower levels of LG compared to their littermates (Fig. 1).

Next, we examined whether individuals that received low and high levels of maternal LG acquired through nonshared experience differ in their neuroendocrine response to acute stress. For this purpose, animals were exposed in adolescence (pnd 28) and adulthood to an acute novelty stressor (10-min exposure to a novel open field). We report that, both in adolescence (Fig. 2a) and adulthood (Fig. 2b), glucocorticoid levels were significantly more elevated in low LG offspring when compared to high LG offspring in response to acute stress. These findings suggest that enduring changes in endocrine response to novelty stress can be "programmed" via variation not only in shared but also in nonshared individual early life history (i.e., individual level of maternal LG). For a detailed description of the methodology and supplementary data of the experiment on stress responsiveness, see Online Resource 2.

\section{Additional considerations}

These findings are reminiscent of previous maternal care studies describing the impact of shared maternal LG on the endocrine response to acute stress (Liu et al. 1997). However, the current findings suggest that very subtle differences in nonshared maternal LG (that are up to tenfold smaller than previously reported differences in LG used to characterize dams within a cohort (Champagne et al. 2003)) appear to have comparable predictive value for later life stress responsiveness. Definitely, further studies are warranted to understand these observations. However, the following factors should be taken into consideration when designing an experiment on this topic.

Features of maternal care repertoire

Although all features of the maternal care repertoire can be measured using this paradigm, it is not always possible to 
Fig. 1 Distribution of maternal LG received by individual pups for each litter (1-7). Shown is the percentage of observations (pnd 1-7) in which each individual pup received maternal LG. Male pups are indicated with male signs, and female pups are indicated with female signs. "Highs" and "lows" within the litter (that displayed a LG percentage of at least one standard deviation above or below the family mean, respectively) are indicated with enlarged male or female signs. Inset Total percentage of LG displayed by each mother

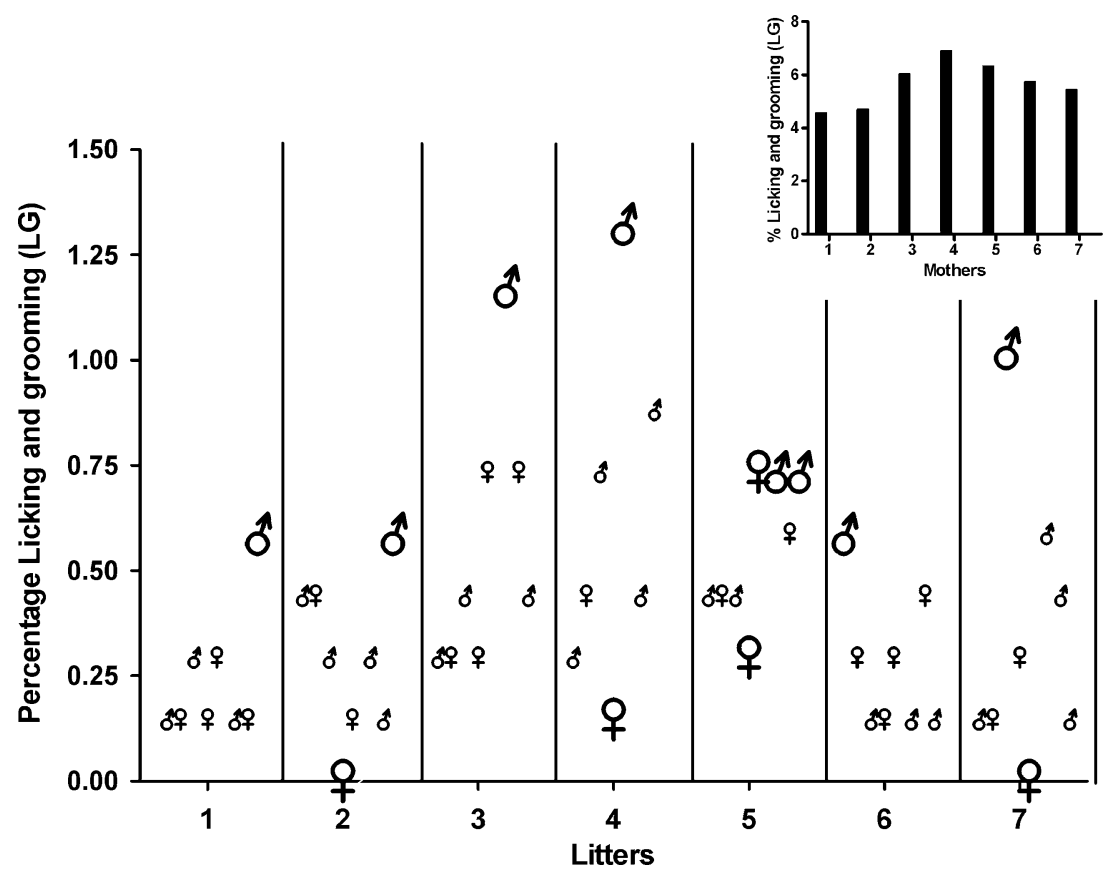

accurately measure their distribution over the individual pups. Arched-back nursing (ABN) is a clear example of this limitation. $\mathrm{ABN}$ is often scored in co-occurrence with maternal LG, but can also be independently affected by early experiences such as EH and can as a consequence exert differential effects on the offspring (Pryce et al. 2001). However, since pups are usually nursed as a group and differences in nursing posture (low-high kyphosis) affect the whole litter, it is unlikely that variation in $A B N$ underlies within-litter differences in later life phenotype. In our opinion, $\mathrm{ABN}$ can be better considered as a shared environmental influence for the pup (Champagne et al. 2003) that is not likely to account for the findings reported here. Nonetheless, we acknowledge that shared maternal factors (i.e., $\mathrm{ABN}$ style of dam) play a role in the development of individual phenotype, although their effects might be modulated by nonshared factors (i.e., individual differences in maternal LG).

Introduction of early handling

Secondly, in order to score individual LG (nonshared factor), a daily marking procedure was used to label and identify individual littermates. Such a procedure inevitably introduces a substantial amount of EH. This implies that besides studying the impact of subtle differences in maternal care within the litter, one has to take into account the well-known effects of EH (see Environmental influences section). One possible bias is that our daily $\mathrm{EH} /$ marking procedure potentially altered maternal care directed toward the offspring. However, we believe that this bias is distributed equally and to a similar extent in all litters studied, and is not

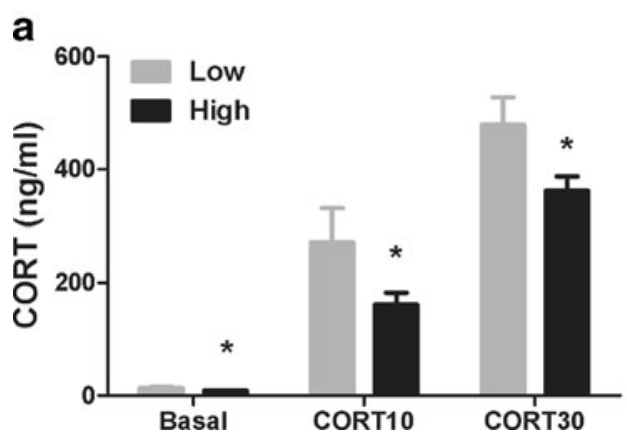

Fig. 2 Plasma corticosterone (CORT) levels of rats characterized as high or low LG within the litter, expressed as mean \pm SEM. ${ }^{*} p<0.05$; $* * p<0.01$. Selected high and low LG animals $(n=13)$ were tested for their endocrine responsiveness to acute novelty stress in (a) adolescence (age pnd 28) and (b) adulthood (age 4.5 months). CORT b

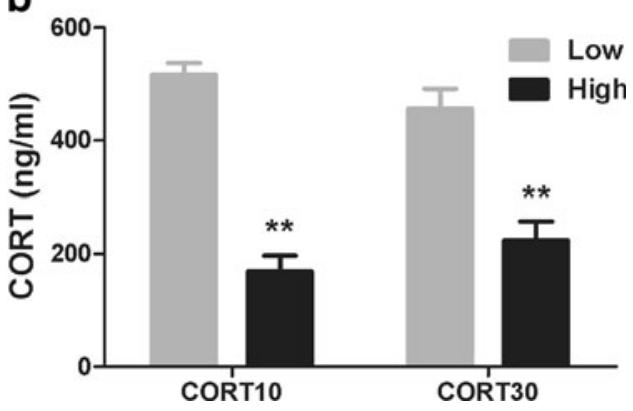

levels were significantly more elevated in low LG offspring when compared to high LG offspring in response to acute stress. Due to technical issues, we are unable to show basal CORT levels of the animals at adulthood; therefore, in $\mathbf{b}$, only stress-induced CORT levels are displayed 
likely to account for the effects observed here. Furthermore, since we observed a substantial amount of variation between littermates in terms of stress responsiveness, we suggest that nonshared differences in maternal care rather than $\mathrm{EH} /$ marking mediate the effects observed here. This scenario is not unprecedented and has been previously proposed by Macri and coworkers for variation in shared maternal care (Macri et al. 2008; Macri et al. 2004).

\section{Underestimation of individual differences in LG}

The Wistar dams displayed relatively low levels of maternal care when compared to previously described maternal LG distribution range in the Long-Evans strain (Champagne et al. 2003). Therefore, the average levels of LG (i.e., 6\%) displayed by Wistar dams in our study fall in the range that would be equivalent to levels displayed by low LG LongEvans dams. In our study, we observed that on average, Wistar dams delivered 40 LG events over the 7-day observation period. From the pup perspective, this might represent on average five LG events per individual pup. Such score might appear too low to reliably categorize individual littermates as low or high LG offspring. We acknowledge that this represents a limitation of our experimental approach, which leads to an underestimation of the occurrence of pup-directed LG events. In the future, this issue can be resolved by increasing the amount of observations per day to achieve a more reliable representation of the actual differences in nonshared maternal LG.

\section{Gender bias}

It is noteworthy that for most of the litters studied, dams displayed a strong gender preference for male over female offspring. Such a preference of the mother for male pups has been shown before (Deviterne and Desor 1990; Moore and Morelli 1979) and proposed to be regulated by testosterone, pheromones, and urinary odor (Moore 1985, 1986). As a consequence, this gender preference resulted in a bias in the distribution of males and females over the selected low (exclusively females) and high LG (almost exclusively males) groups. Since glucocorticoid levels and corticosteroid-binding globulin levels in the blood are modulated by fluctuations in sex hormone levels (McCormick et al. 1998), one has to be careful when interpreting the association between early life maternal LG and later life HPA axis activity. However, we report an association between neonatal LG and glucocorticoid levels as early as adolescence (pnd 28), when the regulatory role of sex hormones on HPA axis functioning is assumed to be low compared to that in adulthood (McCormick and Mathews 2007). Gender differences in endocrine responsiveness at pnd 28 have been shown in some (Hary et al. 1981; Hary et al. 1986) but not all (Sencar-Cupovic and Milkovic 1976) studies. Because of the small sample size, we were unable to reveal a within-gender effect of maternal (nonshared) LG on glucocorticoid levels. Future studies using a higher number of animals and including ovariectomized female offspring will reveal the exact role of nonshared gender-dependent differences in maternal LG during early life on the development of stress phenotype in later life.

For supplementary material on the gender-dependent differences in maternal care, see Online Resource 2.

\section{Conclusion}

In this review, we have provided an overview of some of the scenarios in which environment and genetic variation play a role in the development of individual differences in sensitivity to stress and vulnerability to diseases. Four major points emerge with significant relevance for the field of developmental programming: (1) although environmental influences are recognized as major contributors to the development of stress sensitivity and vulnerability to psychopathology, they do not always lead to the development of diseases; (2) considerable heterogeneity exists between individuals in their response to these environmental factors; (3) complex gene $\times$ environment interplays are hypothesized to account for this phenomenon, a theory gaining momentum in psychiatry; and (4) understanding of the mechanisms by which gene $x$ environment interplays underlie stress sensitivity and disease vulnerability requires the study of their biological consequences as well as identification of the relevant biological pathways (Caspi et al. 2010; Caspi and Moffitt 2006; Rutter 2008, 2010; Rutter et al. 2006).

The several forms of genetic variation do little on their own to cause or alter basic biology and pathways to diseases in response to environmental influences (Rutter 2008, 2010; Rutter et al. 2006). Genetic variation can only exert significant effects via its impact on gene and protein expression, which determines the biologically relevant outcome. Inheritance of particular genetic variants represents one way by which gene and protein levels can be modified. However, environmental influence can also modulate gene expression via epigenetic mechanisms (Weaver et al. 2004). While the fields of developmental programming, neuroscience, and psychiatry have made significant breakthrough on all fronts by uncovering the several ways by which environmental risk factors and genetic variants operate through biological pathways, these fields are still confronted with significant methodological challenges. One aspect of the methodological challenge lies in the ability to develop animal models to address the impact of nonshared environmental influences on the outcome of gene $\times$ environment interplays. The original findings presented in this article suggest that nonshared influences on the 
development of individual differences in sensitivity to stress can be studied in the laboratory.

Furthermore, from an evolutionary perspective, gene $\times$ environment interplays and their related biological mechanisms leading to "programming of the HPA axis" (i.e., alterations in stress sensitivity) are generally meant to be adaptive and not necessarily a substrate for diseases. This is the basis of the "predictive adaptation plasticity hypothesis" (Crespi and Denver 2005; Gluckman and Hanson 2007; Gluckman et al. 2007; Gluckman et al. 2010; Horton 2005). This theory is based on the concept that a developing organism responds to cues (e.g., maternal LG) in its environment by changing certain aspects of its homeostasis (e.g., HPA axis) in order to produce a phenotype that is highly adapted to its current and future environment. This concept led to a currently dominant view in medicine stating that a high degree of "mismatch" between the early and later life environments confers an increased risk to develop adult diseases (Gluckman and Hanson 2007; Gluckman et al. 2007; Gluckman et al. 2010; Horton 2005). There is much evidence to support this view in the field of metabolic and cardiovascular disorders (Gluckman et al. 2007; Prentice 2005). However, in psychiatric research, the validity of this concept is uncertain.

Recent evidence from animal studies suggests that the concept of "mismatch" can also apply to the development of individual differences in stress sensitivity. We have recently shown that the outcome of early experience on stress-related parameters is dependent on later life context (Bagot et al. 2009; Champagne et al. 2008). Specifically, we reported that adult offspring of low LG mothers (considered as a form of adversity) show indeed the "expected" low cognitive performance in a low-stress context. However, in a high-stress context, their performance was better when compared to animals that had received high levels of maternal care, which in turn were impaired under the same stressful conditions (Bagot et al. 2009; Champagne et al. 2008). These findings suggest that the influence of shared and possibly nonshared environmental experiences (as presented in this review) during development might serve as a basis for resilience to stressful challenges in later life in the context of "matched" environments. However, whether such phenomenon plays a role in the modulation of gene $\times$ environment interplays leading to increased susceptibility or resilience to stressrelated diseases remains to be further ascertained.

Acknowledgments The support by the EU funded Network of Excellence LifeSpan (FP6 036894, www.lifespannetwork.nl), the Royal Netherlands Academy of Arts and Sciences, TI Pharma T5209, the Smartmix Programme of the Netherlands Ministry of Economic Affairs, and the Netherlands Ministry of Education, Culture and Science and the Trier-Leiden IRTG program supported by NWO DN 95-429 is gratefully acknowledged.

Conflict of interest The authors have no conflict of interest to report.

Open Access This article is distributed under the terms of the Creative Commons Attribution Noncommercial License which permits any noncommercial use, distribution, and reproduction in any medium, provided the original author(s) and source are credited.

\section{References}

Albers EM, Riksen-Walraven JM, Sweep FC, de Weerth C (2008) Maternal behavior predicts infant cortisol recovery from a mild everyday stressor. J Child Psychol Psychiatry 49:97-103

Anderson LM, Shinn C, Fullilove MT, Scrimshaw SC, Fielding JE, Normand J, Carande-Kulis VG (2003) The effectiveness of early childhood development programs. A systematic review. Am J Prev Med 24:32-46

Andrews MH, Matthews SG (2004) Programming of the hypothalamo-pituitary-adrenal axis: serotonergic involvement. Stress 7:15-27

Anisman H, Zaharia MD, Meaney MJ, Merali Z (1998) Do early-life events permanently alter behavioral and hormonal responses to stressors? Int J Dev Neurosci 16:149-164

Bagot RC, van Hasselt FN, Champagne DL, Meaney MJ, Krugers HJ, Joels M (2009) Maternal care determines rapid effects of stress mediators on synaptic plasticity in adult rat hippocampal dentate gyrus. Neurobiol Learn Mem 92:292-300

Barker DJ (1992a) Fetal growth and adult disease. Br J Obstet Gynaecol 99:275-276

Barker DJ (1992b) The fetal origins of adult hypertension. J Hypertens Suppl 10:S39-S44

Barker DJ (1992c) The fetal origins of diseases of old age. Eur J Clin Nutr 46(Suppl 3):S3-S9

Barker DJ (1997) Maternal nutrition, fetal nutrition, and disease in later life. Nutrition 13:807-813

Barr CS, Newman TK, Shannon C, Parker C, Dvoskin RL, Becker ML, Schwandt M, Champoux M, Lesch KP, Goldman D, Suomi SJ, Higley JD (2004) Rearing condition and rh5-HTTLPR interact to influence limbic-hypothalamic-pituitary-adrenal axis response to stress in infant macaques. Biol Psychiatry 55:733-738

Bonanno GA, Mancini AD (2008) The human capacity to thrive in the face of potential trauma. Pediatrics 121:369-375

Branchi I (2009) The mouse communal nest: investigating the epigenetic influences of the early social environment on brain and behavior development. Neurosci Biobehav Rev 33:551-559

Buss C, Lord C, Wadiwalla M, Hellhammer DH, Lupien SJ, Meaney MJ, Pruessner JC (2007) Maternal care modulates the relationship between prenatal risk and hippocampal volume in women but not in men. J Neurosci 27:2592-2595

Caldji C, Tannenbaum B, Sharma S, Francis D, Plotsky PM, Meaney MJ (1998) Maternal care during infancy regulates the development of neural systems mediating the expression of fearfulness in the rat. Proc Natl Acad Sci USA 95:5335-5340

Carlier M, Roubertoux P, Cohen-Salmon C (1982) Differences in patterns of pup care in Mus musculus domesticus L.- comparisons between eleven inbred strains. Behav Neural Biol 35:205-210

Caspi A, Moffitt TE (2006) Gene-environment interactions in psychiatry: joining forces with neuroscience. Nat Rev Neurosci 7:583-590

Caspi A, McClay J, Moffitt TE, Mill J, Martin J, Craig IW, Taylor A, Poulton R (2002) Role of genotype in the cycle of violence in maltreated children. Science 297:851-854 
Caspi A, Moffitt TE, Cannon M, McClay J, Murray R, Harrington H, Taylor A, Arseneault L, Williams B, Braithwaite A, Poulton R, Craig IW (2005) Moderation of the effect of adolescent-onset cannabis use on adult psychosis by a functional polymorphism in the catechol-O-methyltransferase gene: longitudinal evidence of a gene X environment interaction. Biol Psychiatry 57:1117-1127

Caspi A, Hariri AR, Holmes A, Uher R, Moffitt TE (2010) Genetic sensitivity to the environment: the case of the serotonin transporter gene and its implications for studying complex diseases and traits. Am J Psychiatry 167:509-527

Champagne FA, Francis DD, Mar A, Meaney MJ (2003) Variations in maternal care in the rat as a mediating influence for the effects of environment on development. Physiol Behav 79:359-371

Champagne DL, Bagot RC, van Hasselt F, Ramakers G, Meaney MJ, de Kloet ER, Joels M, Krugers H (2008) Maternal care and hippocampal plasticity: evidence for experience-dependent structural plasticity, altered synaptic functioning, and differential responsiveness to glucocorticoids and stress. J Neurosci 28:6037-6045

Champagne DL, de Kloet ER, Joels M (2009) Fundamental aspects of the impact of glucocorticoids on the (immature) brain. Semin Fetal Neonatal Med 14:136-142

Chapman DP, Whitfield CL, Felitti VJ, Dube SR, Edwards VJ, Anda RF (2004) Adverse childhood experiences and the risk of depressive disorders in adulthood. J Affect Disord 82:217-225

Crespi EJ, Denver RJ (2005) Ancient origins of human developmental plasticity. Am J Hum Biol 17:44-54

de Kloet ER, Sibug RM, Helmerhorst FM, Schmidt MV (2005) Stress, genes and the mechanism of programming the brain for later life. Neurosci Biobehav Rev 29:271-281

Denenberg VH (1999) Commentary: is maternal stimulation the mediator of the handling effect in infancy? Dev Psychobiol $34: 1-3$

Deviterne D, Desor D (1990) Selective pup retrieving by mother rats: sex and early development characteristics as discrimination factors. Dev Psychobiol 23:361-368

Doyle O, Harmon CP, Heckman JJ, Tremblay RE (2009) Investing in early human development: timing and economic efficiency. Econ Hum Biol 7:1-6

Duan J, Sanders AR, Gejman PV (2010) Genome-wide approaches to schizophrenia. Brain Res Bull

Edwards VJ, Holden GW, Felitti VJ, Anda RF (2003) Relationship between multiple forms of childhood maltreatment and adult mental health in community respondents: results from the adverse childhood experiences study. Am J Psychiatry 160:1453-1460

Enthoven L, de Kloet ER, Oitzl MS (2008a) Differential development of stress system (re)activity at weaning dependent on time of disruption of maternal care. Brain Res 1217:62-69

Enthoven L, Oitzl MS, Koning N, van der Mark M, de Kloet ER (2008b) Hypothalamic-pituitary-adrenal axis activity of newborn mice rapidly desensitizes to repeated maternal absence but becomes highly responsive to novelty. Endocrinology 149:6366-6377

Feinberg ME, Neiderhiser JM, Simmens S, Reiss D, Hetherington EM (2000) Sibling comparison of differential parental treatment in adolescence: gender, self-esteem, and emotionality as mediators of the parenting-adjustment association. Child Dev 71:1611-1628

Feinberg ME, Button TM, Neiderhiser JM, Reiss D, Hetherington EM (2007) Parenting and adolescent antisocial behavior and depression: evidence of genotype $\times$ parenting environment interaction. Arch Gen Psychiatry 64:457-465

Francis D, Diorio J, Liu D, Meaney MJ (1999) Nongenomic transmission across generations of maternal behavior and stress responses in the rat. Science 286:1155-1158

Glover V, O'Connor TG, O'Donnell K (2009) Prenatal stress and the programming of the HPA axis. Neurosci Biobehav Rev
Gluckman PD, Hanson MA (2007) Developmental plasticity and human disease: research directions. J Intern Med 261:461-471

Gluckman PD, Hanson MA, Beedle AS (2007) Early life events and their consequences for later disease: a life history and evolutionary perspective. Am J Hum Biol 19:1-19

Gluckman PD, Hanson MA, Mitchell MD (2010) Developmental origins of health and disease: reducing the burden of chronic disease in the next generation. Genome Med 2:14

Gunnar MR, Donzella B (2002) Social regulation of the cortisol levels in early human development. Psychoneuroendocrinology 27:199-220

Gutman DA, Nemeroff CB (2003) Persistent central nervous system effects of an adverse early environment: clinical and preclinical studies. Physiol Behav 79:471-478

Gutteling BM, de Weerth C, Buitelaar JK (2005) Prenatal stress and children's cortisol reaction to the first day of school. Psychoneuroendocrinology 30:541-549

Harlow HF (1969) Agemate or peer affectional system. In: Lehrman DS, Hinde RA, Shaw E (eds) Advances in the study of behavior. Academic, New York

Hary L, Dupouy JP, Chatelain A (1981) Pituitary response to bilateral adrenalectomy, metyrapone treatment and ether stress in the newborn rat. Biol Neonate 39:28-36

Hary L, Dupouy JP, Gregoire I (1986) Effects of castration and testosterone on the pituitary and adrenal responses of the newborn rat to ether inhalation. Neuroendocrinology 42:137-142

Heim C, Nemeroff CB (1999) The impact of early adverse experiences on brain systems involved in the pathophysiology of anxiety and affective disorders. Biol Psychiatry 46:1509-1522

Heim C, Newport DJ, Heit S, Graham YP, Wilcox M, Bonsall R, Miller AH, Nemeroff CB (2000) Pituitary-adrenal and autonomic responses to stress in women after sexual and physical abuse in childhood. JAMA 284:592-597

Heim C, Plotsky PM, Nemeroff CB (2004) Importance of studying the contributions of early adverse experience to neurobiological findings in depression. Neuropsychopharmacology 29:641-648

Heim C, Newport DJ, Mletzko T, Miller AH, Nemeroff CB (2008) The link between childhood trauma and depression: insights from HPA axis studies in humans. Psychoneuroendocrinology 33:693-710

Horton TH (2005) Fetal origins of developmental plasticity: animal models of induced life history variation. Am J Hum Biol 17:34-43

Kalinichev M, Easterling KW, Holtzman SG (2002a) Early neonatal experience of Long-Evans rats results in long-lasting changes in reactivity to a novel environment and morphine-induced sensitization and tolerance. Neuropsychopharmacology 27:518-533

Kalinichev M, Easterling KW, Plotsky PM, Holtzman SG (2002b) Long-lasting changes in stress-induced corticosterone response and anxiety-like behaviors as a consequence of neonatal maternal separation in Long-Evans rats. Pharmacol Biochem Behav 73:131-140

Kapoor A, Dunn E, Kostaki A, Andrews MH, Matthews SG (2006) Fetal programming of hypothalamo-pituitary-adrenal function: prenatal stress and glucocorticoids. J Physiol 572:31-44

Kinsella MT, Monk C (2009) Impact of maternal stress, depression and anxiety on fetal neurobehavioral development. Clin Obstet Gynecol 52:425-440

Kosten TA, Lee HJ, Kim JJ (2007) Neonatal handling alters learning in adult male and female rats in a task-specific manner. Brain Res 1154:144-153

Lehmann J, Feldon J (2000) Long-term biobehavioral effects of maternal separation in the rat: consistent or confusing? Rev Neurosci 11:383-408

Lehmann J, Russig H, Feldon J, Pryce CR (2002) Effect of a single maternal separation at different pup ages on the corticosterone stress response in adult and aged rats. Pharmacol Biochem Behav 73:141-145 
Levine S (1957) Infantile experience and resistance to physiological stress. Science 126:405

Levine S (1994) The ontogeny of the hypothalamic-pituitary-adrenal axis. The influence of maternal factors. Ann NY Acad Sci 746:275-288, discussion 289-293

Levine S (2005) Developmental determinants of sensitivity and resistance to stress. Psychoneuroendocrinology 30:939-946

Levine S, Mody T (2003) The long-term psychobiological consequences of intermittent postnatal separation in the squirrel monkey. Neurosci Biobehav Rev 27:83-89

Liu D, Diorio J, Tannenbaum B, Caldji C, Francis D, Freedman A, Sharma S, Pearson D, Plotsky PM, Meaney MJ (1997) Maternal care, hippocampal glucocorticoid receptors, and hypothalamicpituitary-adrenal responses to stress. Science 277:1659-1662

Liu D, Diorio J, Day JC, Francis DD, Meaney MJ (2000) Maternal care, hippocampal synaptogenesis and cognitive development in rats. Nat Neurosci 3:799-806

Lupien SJ, McEwen BS, Gunnar MR, Heim C (2009) Effects of stress throughout the lifespan on the brain, behaviour and cognition. Nat Rev Neurosci 10:434-445

Lyons DM, Kim S, Schatzberg AF, Levine S (1998) Postnatal foraging demands alter adrenocortical activity and psychosocial development. Dev Psychobiol 32:285-291

Lyons DM, Martel FL, Levine S, Risch NJ, Schatzberg AF (1999) Postnatal experiences and genetic effects on squirrel monkey social affinities and emotional distress. Horm Behav 36:266-275

Maccari S, Morley-Fletcher S (2007) Effects of prenatal restraint stress on the hypothalamus-pituitary-adrenal axis and related behavioural and neurobiological alterations. Psychoneuroendocrinology 32(Suppl 1):S10-S15

Macri S, Wurbel H (2006) Developmental plasticity of HPA and fear responses in rats: a critical review of the maternal mediation hypothesis. Horm Behav 50:667-680

Macri S, Mason GJ, Wurbel H (2004) Dissociation in the effects of neonatal maternal separations on maternal care and the offspring's HPA and fear responses in rats. Eur J Neurosci 20:1017-1024

Macri S, Chiarotti F, Wurbel H (2008) Maternal separation and maternal care act independently on the development of HPA responses in male rats. Behav Brain Res 191:227-234

Matthews SG (2002) Early programming of the hypothalamopituitary-adrenal axis. Trends Endocrinol Metab 13:373-380

McCormick CM, Mathews IZ (2007) HPA function in adolescence: role of sex hormones in its regulation and the enduring consequences of exposure to stressors. Pharmacol Biochem Behav 86:220-233

McCormick CM, Furey BF, Child M, Sawyer MJ, Donohue SM (1998) Neonatal sex hormones have 'organizational' effects on the hypothalamic-pituitary-adrenal axis of male rats. Brain Res Dev Brain Res 105:295-307

McGowan PO, Sasaki A, D'Alessio AC, Dymov S, Labonte B, Szyf M, Turecki G, Meaney MJ (2009) Epigenetic regulation of the glucocorticoid receptor in human brain associates with childhood abuse. Nat Neurosci 12:342-348

Meaney MJ, Aitken DH (1985) The effects of early postnatal handling on hippocampal glucocorticoid receptor concentrations: temporal parameters. Brain Res 354:301-304

Meaney MJ, Szyf M (2005) Environmental programming of stress responses through DNA methylation: life at the interface between a dynamic environment and a fixed genome. Dialogues Clin Neurosci 7:103-123

Meaney MJ, Aitken DH, Bodnoff SR, Iny LJ, Sapolsky RM (1985) The effects of postnatal handling on the development of the glucocorticoid receptor systems and stress recovery in the rat. Prog Neuropsychopharmacol Biol Psychiatry 9:731-734

Meaney MJ, Szyf M, Seckl JR (2007) Epigenetic mechanisms of perinatal programming of hypothalamic-pituitary-adrenal function and health. Trends Mol Med 13:269-277
Meerlo P, Horvath KM, Nagy GM, Bohus B, Koolhaas JM (1999) The influence of postnatal handling on adult neuroendocrine and behavioural stress reactivity. J Neuroendocrinol 11:925-933

Menard JL, Hakvoort RM (2007) Variations of maternal care alter offspring levels of behavioural defensiveness in adulthood: evidence for a threshold model. Behav Brain Res 176:302-313

Merikangas AK, Corvin AP, Gallagher L (2009) Copy-number variants in neurodevelopmental disorders: promises and challenges. Trends Genet 25:536-544

Moore CL (1985) Sex differences in urinary odors produced by young laboratory rats (Rattus norvegicus). J Comp Psychol 99:336-341

Moore CL (1986) A hormonal basis for sex differences in the selfgrooming of rats. Horm Behav 20:155-165

Moore CL, Morelli GA (1979) Mother rats interact differently with male and female offspring. J Comp Physiol Psychol 93:677-684

Moriceau S, Sullivan RM (2004) Unique neural circuitry for neonatal olfactory learning. J Neurosci 24:1182-1189

Moriceau S, Sullivan RM (2006) Maternal presence serves as a switch between learning fear and attraction in infancy. Nat Neurosci 9:1004-1006

Moriceau S, Shionoya K, Jakubs K, Sullivan RM (2009) Early-life stress disrupts attachment learning: the role of amygdala corticosterone, locus ceruleus corticotropin releasing hormone, and olfactory bulb norepinephrine. J Neurosci 29:15745-15755

O'Connor TG, Ben-Shlomo Y, Heron J, Golding J, Adams D, Glover $\mathrm{V}$ (2005) Prenatal anxiety predicts individual differences in cortisol in pre-adolescent children. Biol Psychiatry 58:211-217

Oberlander TF, Weinberg J, Papsdorf M, Grunau R, Misri S, Devlin AM (2008) Prenatal exposure to maternal depression, neonatal methylation of human glucocorticoid receptor gene (NR3C1) and infant cortisol stress responses. Epigenetics 3:97-106

Oitzl MS, Champagne DL, van der Veen R, de Kloet ER (2010) Brain development under stress: hypotheses of glucocorticoid actions revisited. Neurosci Biobehav Rev 34(6):853-866

Ouellet-Morin I, Boivin M, Dionne G, Lupien SJ, Arseneault L, Barr RG, Perusse D, Tremblay RE (2008) Variations in heritability of cortisol reactivity to stress as a function of early familial adversity among 19-month-old twins. Arch Gen Psychiatry 65:211-218

Ouellet-Morin I, Dionne G, Perusse D, Lupien SJ, Arseneault L, Barr RG, Tremblay RE, Boivin M (2009) Daytime cortisol secretion in 6-month-old twins: genetic and environmental contributions as a function of early familial adversity. Biol Psychiatry 65:409-416

Plomin R, Davis OS (2009) The future of genetics in psychology and psychiatry: microarrays, genome-wide association, and noncoding RNA. J Child Psychol Psychiatry 50:63-71

Plotsky PM, Meaney MJ (1993) Early, postnatal experience alters hypothalamic corticotropin-releasing factor (CRF) mRNA, median eminence CRF content and stress-induced release in adult rats. Brain Res Mol Brain Res 18:195-200

Prentice AM (2005) Early influences on human energy regulation: thrifty genotypes and thrifty phenotypes. Physiol Behav 86:640-645

Pryce CR, Bettschen D, Feldon J (2001) Comparison of the effects of early handling and early deprivation on maternal care in the rat. Dev Psychobiol 38:239-251

Pryce CR, Ruedi-Bettschen D, Dettling AC, Weston A, Russig H, Ferger B, Feldon J (2005) Long-term effects of early-life environmental manipulations in rodents and primates: potential animal models in depression research. Neurosci Biobehav Rev 29:649-674

Raineki C, Moriceau S, Sullivan RM (2010) Developing a neurobehavioral animal model of infant attachment to an abusive caregiver. Biol Psychiatry 67:1137-1145

Reiss D, Hetherington EM, Plomin R, Howe GW, Simmens SJ, Henderson SH, O'Connor TJ, Bussell DA, Anderson ER, Law T (1995) Genetic questions for environmental studies. Differential parenting and psychopathology in adolescence. Arch Gen Psychiatry 52:925-936 
Rinne T, de Kloet ER, Wouters L, Goekoop JG, DeRijk RH, van den Brink W (2002) Hyperresponsiveness of hypothalamic-pituitaryadrenal axis to combined dexamethasone/corticotropin-releasing hormone challenge in female borderline personality disorder subjects with a history of sustained childhood abuse. Biol Psychiatry 52:1102-1112

Rosenfeld P, Wetmore JB, Levine S (1992) Effects of repeated maternal separations on the adrenocortical response to stress of preweanling rats. Physiol Behav 52:787-791

Rutter M (2008) Biological implications of gene-environment interaction. J Abnorm Child Psychol 36:969-975

Rutter M (2009) Understanding and testing risk mechanisms for mental disorders. J Child Psychol Psychiatry 50:44-52

Rutter M (2010) Gene-environment interplay. Depress Anxiety 27:1-4

Rutter M, Moffitt TE, Caspi A (2006) Gene-environment interplay and psychopathology: multiple varieties but real effects. J Child Psychol Psychiatry 47:226-261

Saus E, Brunet A, Armengol L, Alonso P, Crespo JM, Fernandez-Aranda F, Guitart M, Martin-Santos R, Menchon JM, Navines R, Soria V, Torrens M, Urretavizcaya M, Valles V, Gratacos M, Estivill X (2010) Comprehensive copy number variant (CNV) analysis of neuronal pathways genes in psychiatric disorders identifies rare variants within patients. J Psychiatr Res

Schmidt MV (2010) Molecular mechanisms of early life stresslessons from mouse models. Neurosci Biobehav Rev 34:845-852

Seckl JR (2008) Glucocorticoids, developmental 'programming' and the risk of affective dysfunction. Prog Brain Res 167:17-34

Sencar-Cupovic I, Milkovic S (1976) The development of sex differences in the adrenal morphology and responsiveness in stress of rats from birth to the end of life. Mech Ageing Dev 5:1-9

Smit-Rigter LA, Champagne DL, van Hooft JA (2009) Lifelong impact of variations in maternal care on dendritic structure and function of cortical layer $2 / 3$ pyramidal neurons in rat offspring. PLoS ONE 4:e5167

Smotherman WP, Bell RW (1980) Maternal mediation of experiences. In: Smotherman WP, Bell RW (eds) Maternal influences and early behavior. Spectrum, New York, pp 201-210

Suchecki D, Rosenfeld P, Levine S (1993) Maternal regulation of the hypothalamic-pituitary-adrenal axis in the infant rat: the roles of feeding and stroking. Brain Res Dev Brain Res 75:185-192
Szyf M, Weaver I, Meaney M (2007) Maternal care, the epigenome and phenotypic differences in behavior. Reprod Toxicol 24:919

Tang AC, Akers KG, Reeb BC, Romeo RD, McEwen BS (2006) Programming social, cognitive, and neuroendocrine development by early exposure to novelty. Proc Natl Acad Sci USA 103:15716-15721

van der Veen R, Abrous DN, de Kloet ER, Piazza PV, Koehl M (2008) Impact of intra- and interstrain cross-fostering on mouse maternal care. Genes Brain Behav 7:184-192

van Oers HJ, de Kloet ER, Levine S (1998a) Early vs. late maternal deprivation differentially alters the endocrine and hypothalamic responses to stress. Brain Res Dev Brain Res 111:245-252

van Oers HJ, de Kloet ER, Whelan T, Levine S (1998b) Maternal deprivation effect on the infant's neural stress markers is reversed by tactile stimulation and feeding but not by suppressing corticosterone. J Neurosci 18:10171-10179

Weaver IC, Cervoni N, Champagne FA, D'Alessio AC, Sharma S, Seckl JR, Dymov S, Szyf M, Meaney MJ (2004) Epigenetic programming by maternal behavior. Nat Neurosci 7:847-854

Weiss LA (2009) Autism genetics: emerging data from genome-wide copy-number and single nucleotide polymorphism scans. Expert Rev Mol Diagn 9:795-803

Weiss LA, Arking DE, Daly MJ, Chakravarti A (2009) A genomewide linkage and association scan reveals novel loci for autism. Nature 461:802-808

Wickrama KA, Conger RD, Abraham WT (2005) Early adversity and later health: the intergenerational transmission of adversity through mental disorder and physical illness. J Gerontol B Psychol Sci Soc Sci 60(Spec No 2):125-129

Wolke D (1987) Environmental neonatology. Arch Dis Child 62:987988

Zhang TY, Chretien P, Meaney MJ, Gratton A (2005) Influence of naturally occurring variations in maternal care on prepulse inhibition of acoustic startle and the medial prefrontal cortical dopamine response to stress in adult rats. J Neurosci 25:14931502

Zubin J, Spring B (1977) Vulnerability — a new view of schizophrenia. J Abnorm Psychol 86:103-126 